\title{
Creative Leadership: design meets neuroscience to transform leadership
}

\author{
Rama GHEERAWO ${ }^{a *}$, Melanie FLORY ${ }^{b}$ and Ninela IVANOVA ${ }^{a}$ \\ ${ }^{a}$ The Helen Hamlyn Centre for Design, Royal College of Art; ${ }^{b}$ MindRheo
}

\begin{abstract}
Creative Leadership is a tripartite leadership model that has been developed and pioneered by Rama Gheerawo, Director of The Helen Hamlyn Centre for Design (HHCD) at London's Royal College of Art (RCA). It evolved over the last decade through observation and experience of the limitations of hierarchical models of leadership across a diverse range of sectors. During this, the three Creative Leadership attributes of Empathy (EMP), Clarity (CLA), and Creativity (CRE), have been explored through a range of primary and secondary research methods. The next stage of research and development involves a multidisciplinary convergence of design thinking with neuroscience that relates to brain plasticity, neural connectivity, and emotional intelligence theory. The aim is to develop a comprehensive grid of key performance indicators of Creative Leadership.

Dr Melanie Flory, neuroscience project partner, explains that the three attributes are learnable, and correlate positively with wellbeing-sustaining values and behaviours in individuals and groups. When the cognitive, emotional and behavioural aspects of these traits are identified and understood, a three-dimensional complementary feedback loop of Learn - Retain - Apply can ensue through experiential learning and development.

This positioning paper presents the evolution, scope and applications of Creative Leadership alongside a discussion on the emerging opportunities for novel design-neuroscience intersection relating to personal, leadership and organisational development, growth and transformation. It also reflects on the pandemic context of 2020.
\end{abstract}

Keywords: creative leadership; design; neuroleadership; cognitive neuroscience; change management; organisational development; multidisciplinary research; transformational leadership

\footnotetext{
*Corresponding author: Rama Gheerawo | e-mail: rama.gheerawo@rca.ac.uk

Copyright (C) 2020. Copyright in each paper on this conference proceedings is the property of the author(s). Permission is granted to reproduce copies of these works for purposes relevant to the above conference, provided that the author(s), source and copyright notice are included on each copy. For other uses, including extended quotation, please contact the author(s).
} 


\section{Introduction}

Creative Leadership is not a leadership strategy. It is a transformational process in which individuals tap into their innate creativity, and the potential to lead themselves and others towards fulfilling the goals and vision of the organisation or project.

\section{A changing landscape of leadership}

The leadership landscape is changing. Whether a small-to-medium enterprise, a large industrial company, or an academic department, leadership increasingly requires a more creative position (Amabile and Khaire, 2008). Creatives are used to being constantly challenged and working to a moving and morphing remit, which makes them adept at adapting to forms of leadership that are more dynamic than static, and incorporating multiple perspectives rather than being single-pointed or one-dimensional. The competitive world of business, however, rarely recognises this, preferring to maintain the status quo of outdated and outmoded forms of leadership that are top-down, process-driven, inflexible, and which do not typically account for people.

Creativity is important, and the economic value of the creative industry sector in the UK has been steadily increasing between 2010 to 2016 at nearly twice the rate of the entire UK economy during that time (Cotton, 2018). In 2016, its economic value stood at $f 100$ bn. In November 2018, through a government press release (HMSO, 2018), the Secretary of State for Digital, Culture, Media and Sport (DCMS), Jeremy Wright, speaking about the phenomenal economic growth in UK creative industries since 2016, announced: 'Today they [sic] have broken the $f 100 b n$ mark ...'. In 2019 the UK creative industries economic value stood at $f 286 b n$, with Mr Wright pledging, 'Our creative industries not only fly the flag for the best of British creativity at home and abroad but they are also at the heart of our economy.' This signals creativity as a new currency for the economy, with powerful potential for applications within leadership.

To date, the term 'creative leadership' largely denotes leadership strategy for the creative sector, or engagement with an artistic mindset in management. On this research project which has inclusivity at its heart, it has been defined as a transformational process which delineates characteristics that can be applied to individuals, groups, organisations, technologies and projects. Whilst it draws on practice from the creative industries, it transcends disciplines, roles and institutions. This paper presents the current status and recent developments of this research enquiry, ensuing from an unfolding collaboration between design and neuroscience researchers.

In parallel, empathic leadership emerges as a reflective, quieter and more collaborative position, and is being seen as important in the changing world of leadership theory and practice. This is also noticeable within design practice as a growing ambition over the last two decades, and endorsed by McGinley (2012) who maintains that an empathic stance is essential for designers developing their own practice. Linking an organisation's direction to the personal individual perspectives and aspirations of its employees can help align ambitions and engender a more focused and vibrant workforce.

\section{Leadership in a crisis}

The Covid-19 pandemic has brought to the fore a primary modus operandi of conservative and hierarchical leadership by governments across the globe. This is a leadership approach in itself which is set apart from any political affiliation. 'This is how you do it', 'this is why you do it', reinforced by imperative statement hashtags, is the order of the day.

In crisis management where fast-acting and immediate mitigation measures are vital to saving human life and escalation of a problem and its effects, this line of action can indeed provide the guidance and level of direction needed amidst times of uncertainty, limited clarity, and systemic instability. However, this style of leadership could be considered dictatorship, if not fuelled by underlying empathic approaches in understanding the complexity of the problems and solutions. The NHS and government ascribe to empathy being an essential first step to developing clarity regarding the way forward (Howick, 2019).

In the wake of an almost global lockdown informed by scientific evidence that prognosticates the escalation of loss of human life prior to any reprieve, we see a secondary model of leadership emerging behind the scenes that is strongly aligned with creativity and creative thinking. This emergence is driven by the need to bring about immediate day-to-day operative and strategic solutions that directly relate to improving personal experience and the need to be a part of the solution to save lives. An example of this in the UK was clearly displayed when medical staff with their back up against the wall, balanced patient care duties and the inner call to save lives, with the need for self-preservation and personal safety. TV channels reported how frontline staff took to using bin bags and 
home-laundered protective clothing and face masks in an attempt to be safe and get on with the business of serving the nation's sick through the machinery of the NHS.

These, and similar activities, are examples of leadership initiatives and qualities that emerge from within the individual, provoked by a felt user-need that focuses and drives energy towards the emergence of clarity and the blossoming of new insights and pathways to solution-finding and innovation-based thinking. Creative Leadership $(\mathrm{CL})$, with its tripartite unison of Empathy, Clarity, and Creativity, is clearly a model that falls within the second category. This way of leading from within, irrespective of status, is highly participatory and contributory, thereby enriching the whole.

In the current global crisis, this is borne out every day as journalists tell stories of individuals, organisations, and communities immersing themselves in team-spirited creative thinking and efforts to ease, console, alleviate, solve, transform and influence in some small way, the pain and fear generated by the reality of the threat to human life. This empathy-based participation is not lost in time and space. Not for the individual or the collective. It is an empathy with purpose. In its own wake it leads to creative objectivity on different levels. From banding together to explore and formulate new hypothesis, to being a part of a local food-provision volunteer group, each participant requires little incentive to be a part of the solution whilst acting safely.

Covid-19 has shown us that leadership styles must evolve. Science and art must collaborate and complement. The authors believe that $\mathrm{CL}$ is not just about leadership, but a solution to the huge job of people-centred design and innovation that is here to stay. If ever there is a new normal, design, creativity and innovation is at the centre of it. Everyday this reality is showing up for the sole trader and the multibillion-dollar corporation.

\section{Driven by Design}

The programme of $\mathrm{CL}$ research grew from Inclusive Design (ID) practice at The Helen Hamlyn Centre for Design, which was defined in 2000 by the UK Department of Trade and Industry as 'products, services and environments that include the needs of the widest number of consumers', marking it as a creative strategy for business, and linking social equality to innovation. ID has been described in various ways - as a practice, methodology, philosophy or technique - but a key effect is that it is internationally recognised and used by governments, industry, designers, policymakers, and social and creative organisations. The idea was articulated by Coleman (1994) at the International Ergonomics Association's 12th Triennial Congress and now forms the underlying focus at HHCD, which Gheerawo now directs. Over 300 ID projects have been conducted with around 200 organisations forming an evidence-base for empathic and creative practice.

ID shares its ideology with Universal Design (UD) and Design for All (DfA). All three have their origins in designing for older or disabled people, but have evolved to embrace varying uses, definitions and applications. As Vavik \& Gheerawo (2009) note, different cultural, historical, and political factors across the world have affected the precise way in which these ideals have been interpreted and expressed.

People-centredness and empathy are widely accepted components of design approaches as noted by several researchers and practitioners such as Beverland et al. (2015), Liedtka et al. (2017) and Newton et al. (2016). Gothelf (2017) describes the need for an empathic look at users or consumers and Curedale (2015) notes that the field of design has evolved to become less about making people want things, and more about answering human need.

$\mathrm{CL}$ started with a single insight - that we need more creatives in leadership positions and that the world would benefit from leaders who are more creative. This led to an enquiry into the specific qualities designers could bring to leadership; the value of their creative capacity in navigating complexity, ambiguity and uncertainty; and the opportunities for design tools and processes, particularly those of human-centred and collaborative approaches, to develop leadership capacities in individuals and organisations (Figure 1).

The concept was born in 2007, whilst Gheerawo was delivering ID projects and workshops in Trondheim, Norway. Although the concept was not defined until later, he recalls that this was the point in time when $\mathrm{CL}$ began to form as a domain in its own right, quite separate from ID and Design Thinking - the latter being described by Brown (2008) as 'a discipline that uses the designer's sensibility and methods to match people's needs with what is technologically feasible and what a viable business strategy can convert into customer value and market opportunity'. CL, on the other hand, was conceived by Gheerawo as a framework to enable designers to step into leadership positions, and a more creative stance for leadership as a whole. 


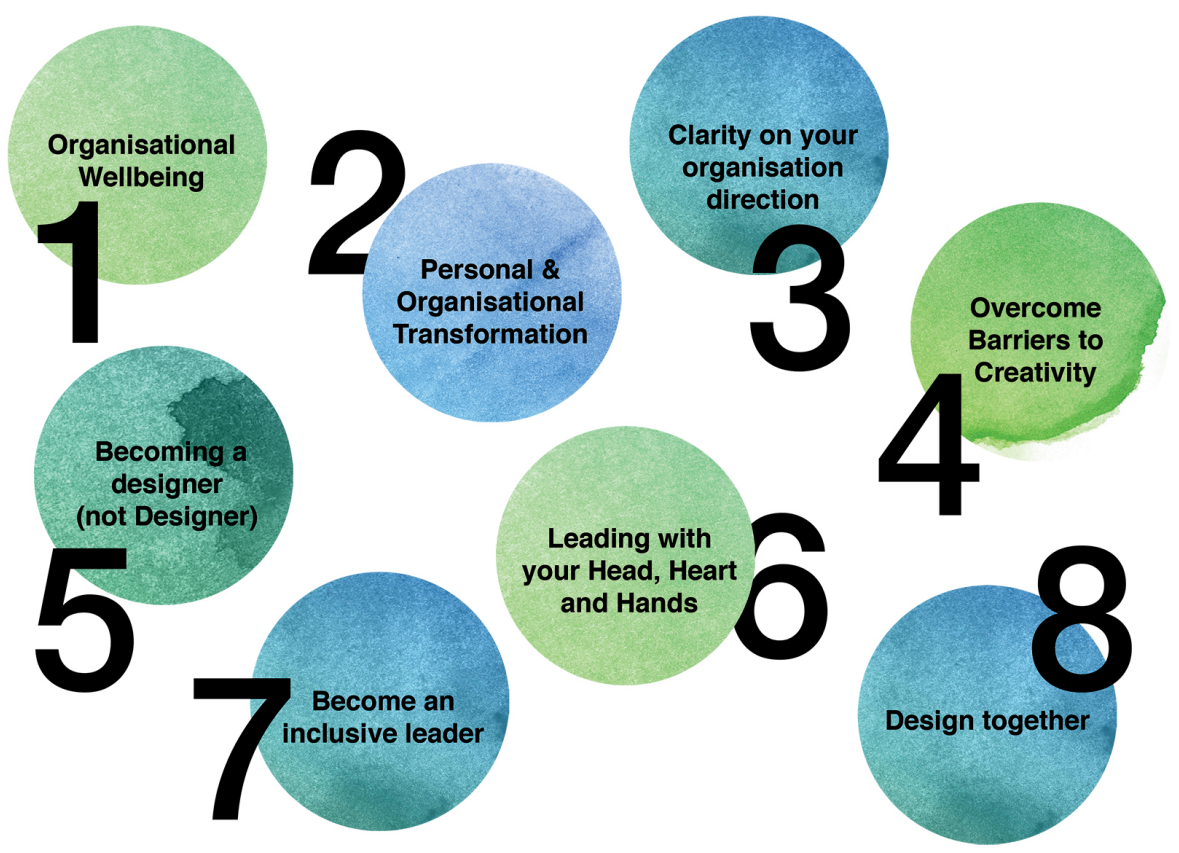

Figure 1. Creative Leadership foundational principles

These ideas grew from Gheerawo's experience in personally leading over 100 design projects with government, business and the third sector - from small and medium enterprises, to large multinationals - where the three values of Empathy, Clarity and Creativity began to emerge as essential to developing products, services and systems that aimed at improving people's lives. Two examples of such projects are presented below. Although specific components of the three values were prominent in each project, the authors' evolving CL practice highlights that they all need to be present throughout an entire project, to ensure meaningful outcomes with a full and vibrant effect.

\section{Re-designing the London taxi}

'The Future London Taxi' project was a collaboration between HHCD, the Intelligent Mobility Design Centre at RCA, and a Turkish vehicle maker Karsan. Empathy - at a number of different levels - was important in informing the project brief and drawing together the different political, creative and engineering entities involved. The project brought in service users with a range of mobility issues, requiring immersive and empathic techniques to be deployed. An advisory group of experts was created to enable wider advocacy. Central to the process was the use of a rough prototype to enable co-creation with a range of people, which allowed changes to be made in 'real time'. Participants remarked on this as positive - their ideas and comments were seen to demonstrably impact the physical design.

An important user group was drivers, because for many cab drivers, their vehicle doubles as an office, a place of rest, a workspace, and a canteen. The London Taxi Driver Union were heavily involved in the project, creating a sense of co-ownership of the creative process. The drivers themselves defended the design ideas as their own in public fora that occurred at London City Hall. Driver wellbeing was seen as important and an overriding sense of empathy informed the research and creative outputs. The result was the organic development and delivery of inclusive design. More than 150 changes were proposed that would make London's iconic black taxis a more creative, accessible, and luxurious proposition.

\section{Using Al to support communities with mental health}

'Our Future Foyle' is a city-scale, socially transformative project based along six miles of riverfront along the River Foyle in Derry/Londonderry, Northern Ireland. This three-year project began in 2016 as research commissioned by Public Health Northern Ireland to look at improving the mental wellbeing of the local population. The river's estuary separates Northern Ireland from the Republic of Ireland and is still a disputed territory. In this area suicide rates are the highest in the UK, and the swift-running River Foyle has drawn many troubled people to its bridges. HHCD worked with the community to deliver some transformative interventions to the river area. 
'Foyle Reeds' is a public interactive art sculpture that doubles as a suicide prevention barrier. 'Foyle Aware' is a media campaign, also designed by HHCD, to improve awareness of mental health and help the community identify people in need of support before a crisis point is reached; and 'Foyle Bubbles' are portable spaces along the river bank and bridges occupied by existing organisations and individuals from community, arts, and commercial sectors trained in mental-health awareness.

The Future Foyle project aimed to draw in an estimated $f 15 \mathrm{~m}$ in European, governmental, and industry funding. At the heart of the project was the need for Clarity - an understanding of the social, economic and community factors that drove the project team. Clear problem definition, clear communication with the community, and enhanced Empathy in dealing with a highly sensitive subject were important in building trust at all levels, from the locals in the neighbourhoods through to the political decision-makers. Throughout this project, the practice of $\mathrm{CL}$ in the designers' thinking and behaviour helped realise 'Our' in the 'Our Future Foyle' project.

\section{The three values of Creative Leadership}

The term 'creative leadership' was first used in the 1950s (Selznick, 1957), and since then has been predominantly associated with a style of leadership that encourages creativity in devising new business strategies and models (Puccio, Mance \& Murdock, 2011; Sohmen, 2015; van Velsor, McCauley \& Ruderman, 2010; Vernooij \& Wolfe, 2014), in organisational development and change management (Sternberg, Kaufman \& Pretz, 2003), and in building environments and teams that use creative processes in innovating products and services (Mainemelis, Kark \& Epitropaki, 2015; Mitchell \& Reiter-Palmon, 2017; Mumford at al., 2002). In the creative industries, 'creative leadership' is synonymous with visionary thinking and being a pioneer in a respective design or creative field (Berlin School of Creative Leadership, 2017).

In all cases, engagement with an artistically creative mindset is of the essence, and in 2010, an IBM study of global CEOs, established that business leaders themselves acknowledged creativity as the top leadership quality that would require attention and development. In recent years, this has formed the basis for new leadership and innovation programmes that teach creative thinking and skills, with a view to 'unlocking leadership potential' (HBR, 2010).

Gheerawo's CL model speaks to a wider need for personal and organisational development, with applications that balance human and technological factors and centre on new and enduring values. Gheerawo elaborates that while traditional notions of leadership are top-down, hierarchical, and reliant on solid structures and levels of management, his design practice, lived experience, and deep reflection over the last twenty years indicated a need for a more quiet form of leadership, which centred on people as the living body of an organisation, and the driving force behind an undertaking, or project.

The purpose was to develop a programme of delivery in areas of personal and organisational development, as well as practical applications in innovation and project management, demonstrating appreciation and knowledge relating to the ever-emerging need and demand for innovative and culture-building leadership through experiential learning and development.

As illustrated above, the model has been shaped and honed over the last ten years to arrive at a theory, through practice. This led to the formulation of the tripartite model of Empathy, Clarity and Creativity, based on the principles that: 'everyone has leadership potential; creativity is defined as a universal ability to develop solutions that positively impact ourselves and others; empathy is the hallmark of a $21^{\text {st }}$-century leader; and clarity is the link that aligns vision, direction, and communication, in a personal undertaking, organisation, or project.' (Gheerawo, 2018; Gheerawo, 2019).

The $\mathrm{CL}$ components of Empathy, Clarity and Creativity essentially address the need for individuals to adapt and succeed in a VUCA ${ }^{2}$ environment - notwithstanding the current pandemic - predicted by John Chambers, CEO of CISCO (McKinsey, 2016), who says: 'Business models will rise and fall at a tremendous speed. And it will be a brutal disruption, where the majority of companies will not exist in a meaningful way 10 to 15 years from now.'

\section{Neuroscience meets Design and Leadership}

Why does every generation feel that the world they live in is in continuous flux, and that over the last fifty years alone, that change is occurring with unprecedented rapidity and far-reaching global effect? Could this have anything at all to do with the evolutionary history of the human brain?

\footnotetext{
${ }^{2}$ Volatile, uncertain, complex and ambiguous
} 
The evolutionary sciences tell us that the size of the human brain has fluctuated over the past 3 million years. However, a spurt increase in brain size occurred between $800,000-200,000$ years ago (George et al., 2018) which is about the size of the human brain today. It so happens that this time period is marked by dramatic climate change. The need of the hour for our ancestors was for greater ability and capacity to process new information, make appropriate decisions, and take actions that raised the potential for survival and continuity of self, one's immediate group, and by implication, the human race.

This ability of organic material - aka cellular matter - to morph and mould in response to the environment within which it exists and operates, is called plasticity. The term used to describe this quality in the brain is neuroplasticity (Begley, 2009). What's pertinent to this paper is that brain changes occur on an individual and collective basis as we go through the motions of everyday life.

Following close on the heels of brain evolution is the traceable history of human innovation and design thinking in response to felt and perceived need. The biological response to 'come out of the cold' or 'make a fire', is borne out by archaeological evidence of cave dwellings in France and Germany, which have been carbon dated to some 400,000 years ago (Pobiner, 2016). Travel forward to 100,000 years ago, and we see hominin shelters decorated with ornaments made of bone and shell. From the hand-hewn dwellings of our ancestors to the cityscapes of today, the environment - brain evolution - innovation - design interrelationship, is undeniable.

For as little over a decade now, neuroscience research in organisational change and development has involved brain-function studies of real-time leadership scenarios with innovation and creativity tasks (Limb \& Braun, 2008; Fink et al, 2009; Molenbergs et al, 2017), amongst others. Sporns, Tononi \& Kotter (2005) maintain that leadership studies involving mapping of brain activity - known as connectivity mapping - allow for objective observation, measurement and interpretation of connectivity and brain plasticity relating to leadership thinking and behaviours.

Creativity, to one degree or another, is a ubiquitous and complex feature of human thought and behaviour (Limb \& Braun, 2008). Connectivity studies by Limb and Braun (2008) evidence that specific areas of the brain work together during creativity and innovation tasks. In popular parlance, this is called firing (activating) and wiring (connecting) together.

Connectivity studies involving creative improvisation tasks (Limb \& Braun, 2008), creative problem solving (Fink et al, 2009) and inspirational leadership (Molenberghs et al, 2017), show that specific areas in the brain are activated when participants are given creative or innovation tasks, and that these activations correlate to specific types of cognition such as reflective thinking and decision making. The steadily growing body of neuroscience research evidence posits a strong argument for collaboration between neuroscientists and designers in developing theory, content and design of education and training materials that enable the firing of specific neural networks associated with generating targeted leadership traits and behaviours. It extends the scope for intersection and cocreation between the two disciplines in areas such as UX, evidence-based design of learning materials, applications building, cognitive and emotional intelligence training, and inclusion-based factors such as cultural nuance and workplace environment.

\section{Neuroscience and Creative Leadership}

Gheerawo's Creative Leadership is constructed on the foundational premise that everyone is a leader and our whole lives are filled with opportunities for leadership growth. Flory explains that this perspective is especially empowering and timely in confronting the complexities of a pan- and post-Covid-19 world, where uncertainty coupled with precariousness, give rise to the desperate need for Empathy, Clarity and Creativity to address the reality and looming threat of demise, collapse, chaos and finger-in-dyke scenarios.

Even during times of comparative stability, biological and social systems are in a continuous state of flux which embodies features of both, permanence and change (Bohm, 2002; Heraclitus, 2013). Through Figure 2, Flory (2018) illustrates the value of Creative Leadership in the context of organisational development. She explains that the grey triangles depict organisational responses to ever-changing PESTLE ${ }^{3}$ factors. The four-part diamond presents the ethos, enablement and effect mediated by $\mathrm{CL}$ on an individual and organisational level.

\footnotetext{
${ }^{3}$ Political, economic, social, technological, legal, ethical / environmental
} 


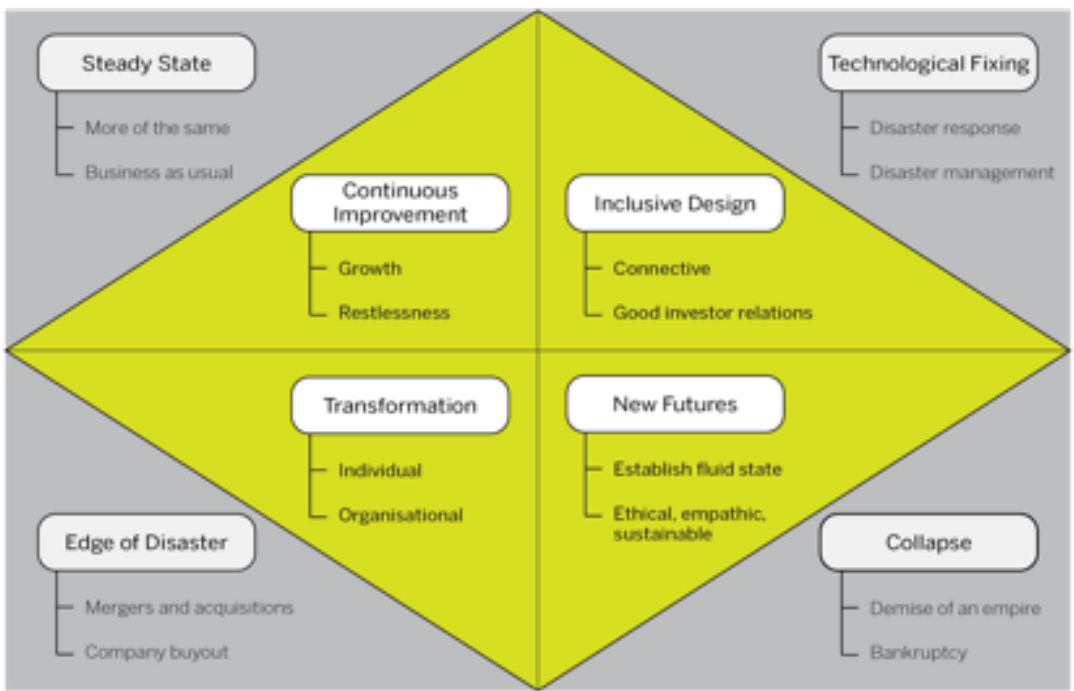

Figure 2. Creative Leadership in Context (Flory, 2018)

Empathy, Clarity and Creativity are sustaining human values in themselves. Several branches of neuroscience are steeped in research enquiry relating to these human traits in order to understand their value and effect not just on one's own thoughts, behaviours and feelings, but also on how their expression can lead to better relationships and outcomes for all (Decety and Ickes, 2009). Organisational leadership and development primarily rest on this premise.

\section{The Neuroscience of EMP, CLA, CRE}

Creative Leadership is first and foremost a practice in empathic response to the need for change, innovation and transformation. Empathy-led exploration and understanding puts people first, and is the 'necessary revolution' (Senge et al., 2008) to creating a sustainable world for people and the planet. Because empathy is a felt and observable human trait, it can be continuously developed and refined, and people at every level in the organisation can become transformers of the businesses and communities they are a part of.

Research evidence from the emerging field of social neuroscience, which studies brain activity whilst people interact, is beginning to reveal new verification about what makes a good leader (Goleman and Boyatzis, 2008). These researchers maintain that great leaders are those who understand the importance, value and need to behave in ways that powerfully leverage human connectedness, both, with oneself (intra-connectedness) and the group (inter-connectedness) - viz. empathy.

Whilst a comprehensive discussion of neurobiological and social neuroscience evidence relating to the traits of creative leadership lie outside the scope of this paper, it is pertinent to note that the evidence emerging over the last two decades relating to empathy and the empathy spectrum of emotion and behaviour - e.g., sympathy and compassion (Trieu et al., 2019), using Functional Magnetic Resonance Imaging (fMRI) and self-assessment tasks, have led to rigorous evaluation and evidence that clearly show empathy can be acquired and developed by taking advantage of neuroplasticity. Trieu et al. (2019) maintain that understanding the neurobiological basis of empathy can help inspire clinical staff to improve their intra- and inter-connectedness skills and strategies for better patient care and experience. These findings can help inform learning and development of empathy for leaders and designers.

In relation to creativity, a critical review of fMRI studies published from Oct 2010 - Oct 2011 carried out by Sawyer (2012), identified distinct brain circuits that correlate with higher order cognitive processing, i.e., different types of creative cognition. Sawyer (2011) concluded that cognitive neuroscience has the potential to contribute a valuable perspective to creativity researchers and teachers. Almost a decade later, Green, Freed and Sawyer (2019) who have a continuous and well-respected record of research in this field, are convinced of the advantages of collaboration between cognitive neuroscientists, creativity researchers and creativity and design educators to help advance understanding and education, and build applications that incite creative thinking and behaviours in schools and the workplace. They stress the importance of teaching and learning how to activate types of creative thinking (e.g.: creative insight, hypothesis generation, story generation, story arcing, mind wandering, etc.), and advise: 'continued interdisciplinary collaboration has the potential to further advance our understanding of the 
mental processes and structures associated with creative thought and behaviour.' (Green, Freed and Sawyer, 2019, pp. 130)

The subject of mental clarity is vast and straddles theory and research across a number of sub-domains within neuroscience. These range from the neurobiology of dementia and the autism spectrum disorders, to mathematical ability and problem solving in early education.

In this early dawn of collaboration between design and neuroscience, it is proposed that a contained approach to collaborative research and design relating to enablement and actuation of mental clarity, be taken. Flory proposes that this can be achieved by exploring and examining the research evidence relating to the theory, learning and practice of psychological flow, which offers a one-place evidence-based repository relating to clarity, rather than the herculean task of sifting through the myriad of specialised clinical condition studies relating to mental clarity.

Mihaly Csikszentmihalyi, the father of flow concept and theory (1975), used the term 'flow' to describe the optimal human experience of being in a highly focused mental state whilst fully engaging in an activity - cognitive and/or behavioural. The resultant unique brain state observed in EEG neurofeedback studies (Gruzelier, 2014a; 2014b; 2014c), correlate with specific brain activation; increase in subjective reporting of happiness and enjoyment; and increased productivity. Most human beings have experienced the flow state at one time or another in activities as varied as organisational scenario planning and writing, to jogging and playing football.

Cognitive and behavioural capabilities that correlate with flow state, which can be taught and learned, include fluidity in attention and action, intrinsic motivation, clarity of goals, and aha moments relating to creativity and invention (Csikszentmihalyi, 1996). All of these qualifiers are explicitly and implicitly present in Gheerawo's definition of clarity (see Table 1), and is borne out by Flory's observation of workshops executed by Gheerawo and his team at the HHCD.

Flory has already begun the groundwork for developing a multi-level model of $\mathrm{CL}$, which in turn will organically inform a psychometric KPI test of CL for individuals and organisations (Cipresso \& Immekus, 2017).

\section{Research and theory-building}

Over the last decade, the CL programme of research and development has constituted a range of activities, including: testing in the field through executive education; interdisciplinary research through the coming together of design and neuroscience researchers; a pilot test; qualitative research through interviews; and delivery of design and innovation projects; all of which have helped to refine and hone the model, grow the evidence-base and identify opportunities for further research and applications development.

\section{Experiential learning}

To date, the $\mathrm{CL}$ model has been trialled via delivery of over fifty executive education and bespoke workshops with over 5,000 people across the UK, Norway, Denmark, Poland, Bulgaria, US, China and Singapore among others, and the oversight of more than 250 people-centred projects across private, public and voluntary sectors of the economy. While not formalised as research, these workshops have allowed for direct testing of receptivity to the $\mathrm{CL}$ concepts across demographics, observation of how the $\mathrm{CL}$ principles are expressed in group interactions and creativity tasks, as well as testing and refining design methods and tools that help people understand and practice attributes associated with Empathy, Clarity and Creativity.

Although the teaching and materials were drawn from design, participant groups have ranged from large multinational corporations to NGOs and start-ups, civil servants and policymakers, academic institutions, designers, marketeers, and entrepreneurs working within the finance, logistics, technology, pharmaceutical, health, wellbeing, social and creative sectors.

Feedback from the delivery to date has been widely positive, with over $90 \%$ of individuals and organisations who take part, relating to, and endorsing the three $\mathrm{CL}$ attributes as core and essential to their ability to serve, both, shareholders and stakeholders alike.

Creative Leadership is a 'must' for leaders who want to break down barriers and be respectful of the emerging changes being brought about in leadership influenced by those coming into the workplace for the first time, who will not tolerate the top down approach of yesteryear. (Workshop participant, November 2019)

Participants report feeling engaged, responsive and inspired, as well as finding personal resonance with the concepts and their applicability. Post-workshop, participants have shared how the workshops have affected their 
personal life and transformed their professional outlook, which fulfils a primary intent of Creative Leadership, which is to enable people 'to tap into their inner selves, their inner voice, their inner knowledge, giving them permission to be their creative self.' (Oral history interview with Gheerawo, Ivanova, 2018)

\section{Interdisciplinary-led Research Enquiry}

The research questions shaping the interdisciplinary inquiry, theory-building, and subsequent design of educational and learning content, approach and applications are as follows:

i) What is the neuroscience evidence-base proposing and affirming about organisational leadership, in general; and human cognition, emotion, and behaviour relating to clarity, creativity and empathy, in particular?

ii) What kind of education and training would help activate these traits on an individual and collective level, and ensure long-term memory retention and practice of these traits?

\section{iii) What are the design methods and processes that can achieve the objective outlined in ii) above?}

In addressing these questions, a multiple-levels (cognitive, affective, behavioural) approach to identify, categorise and order the correlates of thought, emotion and activities relating to clarity, empathy and creativity, is a first-level approach that will give access to formulation of key performance indicators that are identifiable and measurable. The corollary of this is that new learning and development methods, materials, and applications informed by this evidence-base can be designed so as to educate and train individuals and groups in being changeready, intelligently adaptable, responsive and leading change and innovation.

Flory posits that from a neuroscience perspective, educating and training people in 'how to regulate cognition, emotion and behaviour in specific circumstances', thereby deliberately activating specific neural networks, is essential for long-term memory retention and intelligent exploration leading to clarity, coupled with relevant and appropriate expression of empathy, creative thinking and creativity. The following diagram (Figure 3) depicts how designing a multi-level learning experience, can lead to long-term memory retention and relevant creative application.

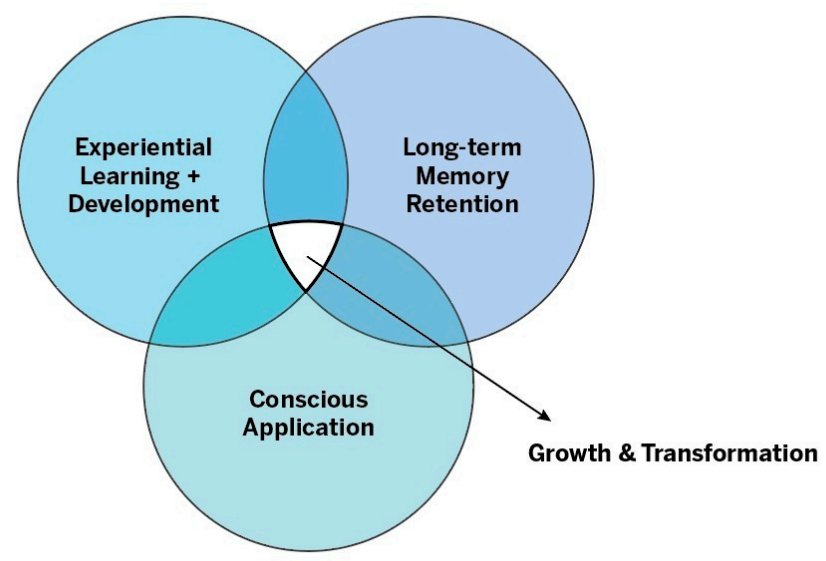

Figure 3. Effect of multi-level learning experience

The figure above clearly demonstrates the implications and importance of cross-disciplinary collaboration between neuroscience and design, and provides an opportunity for the introduction of new methods and materials in research, teaching, and personal and global change management programmes.

\section{Formalising definitions and a pilot test}

An integral part of the research was formalising definitions for Empathy, Clarity and Creativity in relation to leadership (Table 1), to enable understanding of their multiple applications in enterprise and education, not as abstract concepts or principles, but as spectra of capacities and attributes that can be exercised and developed.

This was considered a steppingstone in the research process, because the precision required to develop tight definitions for the subject of research 'feeds back into the research process, provides a jumping off point for 
further investigation, and can also be a valuable output of research' (Haynes et al.; 2015). The process involved a methodical review of the literature of neuroscience and organisational development of Creative Leadership, and feedback and insights from the research activities described in this section.

Table 1. Creative Leadership definitions - Version 1 used for the Pilot Study

Empathy is the ability to recognise, understand and reflect on the thoughts, feelings and behaviours of others. Simply said, it's the ability to put ourselves in the 'shoes' of another and understand what their experience might be like.

Clarity is having a clear understanding of the vision and direction of the organisation, or project. It is the ability to effectively communicate this to a variety of audience. To be clear is to maintain an accountabilitymindset that supports the growth of the individual, team and organisation.

Creativity is the ability of an individual or group to utilise their intellect, skills and resources to create solutions, services and products that are novel, useful and relevant.

Flory (2018) designed a pilot study to assess whether a mixed-sector group of individuals could relate to Empathy, Clarity and Creativity as traits and behaviours that they could identify in themselves in relation to their day-to-day work life and leadership, based on the above definitions. A simple visual tool (Figure 4) was given to participants to plot a self-assessment of personal application of these traits in the workplace.

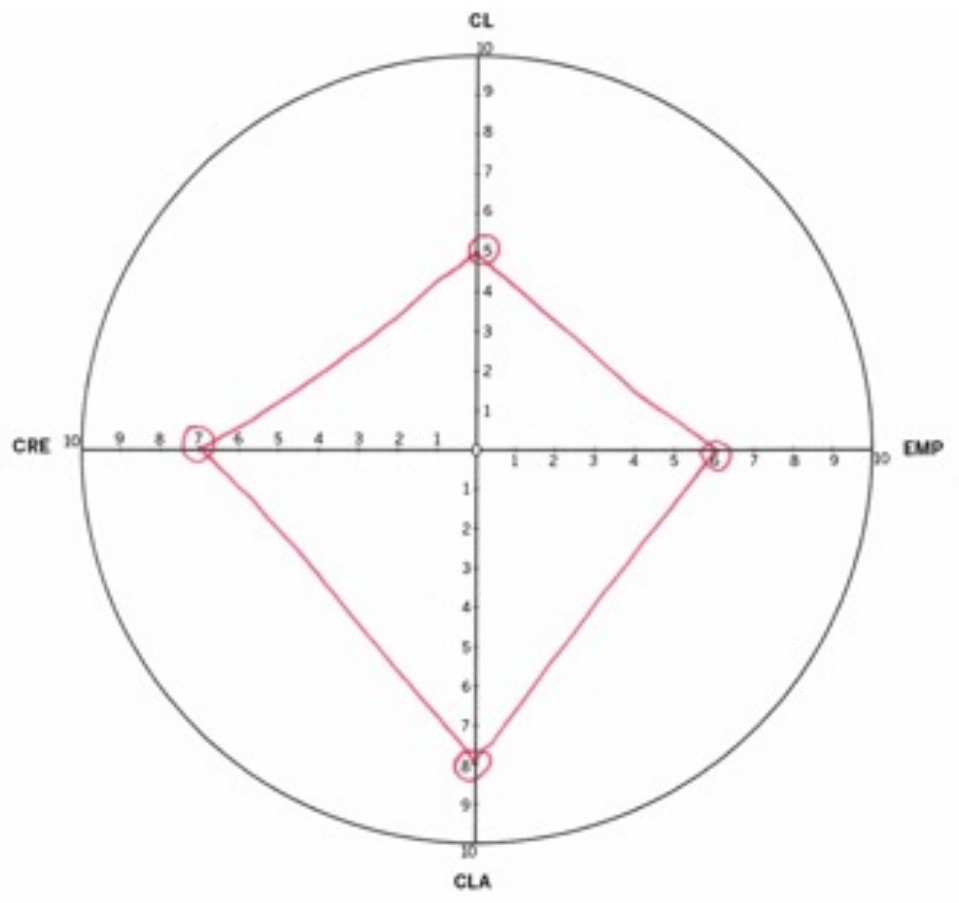

Figure 4. Pilot test: Measurement tool (self-assessment by participant)

The pilot study was implemented at Innovation for All 2018 - an Inclusive Design conference for business and the public sector hosted by DOGA (Design and Architecture Norway) in Oslo (2018). A major advantage of running this mini pilot was that participants represented an opportunistic sample $(\mathrm{N}=36$; Male $=16$; Female $=20)$. Consequently, an unintended but valuable outcome of the pilot was the discovery of relatability to these traits across sectors, in diverse leadership and organisational cultures, and their reported application in everyday personal and professional settings.

This led to a proposition for a three-dimensional model of Creative Leadership that will form the basis for KPI measurement and a comprehensive multi-levels approach to education and training in these leadership attributes. 


\section{Qualitative interviews}

In 2018, Ivanova joined the Creative Leadership research to help grow and capture the evidence-base for Gheerawo's CL model. This included a series of interviews with leaders and senior management across the public, private and government sectors (Ivanova, 2018). The first set of semi-structured interviews examined the organisational culture and leadership style, ideas of 'great' leadership and role models, and whether components of Creative Leadership were partially or fully in practice in the six organisations specifically chosen for this research ${ }^{4}$.

Findings from these interviews indicated a shared recognition of changing organisational culture where enabling others to fulfil their potential, a coaching rather than directive approach, breaking down siloes, and incorporating play and experimentation to spark creativity, were paving the way for new modes of leadership based on collaboration, inclusion, disruption and accountability.

Empathy, while highlighted in the recent literature as a core capability of twenty-first century leadership, was still misunderstood, or underappreciated, by dismissing it as a 'soft skill' rather than a key attribute. For example, male leaders reported that they recognised the need for diversity in senior management and at board level, however struggled to imagine, or implement a long-term plan of action because of lack of prior experience of more inclusive setups and empathy-driven approaches. In contrast, aspects of Clarity, e.g., the importance of setting a vision and being a good communicator were well appreciated among the interviewees, with CEOs creating platforms that enabled them to communicate company vision and strategy across the organisation, as well as implementing feedback loops and processes.

\section{Overcoming barriers}

These interviews supported an ongoing area of research interest which is mapping barriers to $\mathrm{CL}-$ ranging from internal barriers, such as ego-centric mindset, lack of understanding of self-worth and value, and emotional barriers, e.g., fear and stress, to external factors, e.g., time, resources and technology. This is where the pairing of design and neuroscience can enable development and upskilling on a personal level, where 'quick-fix' solutions would prove unsustainable in the longer term. Flory asserts that exercising Empathy, Clarity and Creativity in thought, behaviour and emotion, entrains functional changes in the brain. Continued practice and contextual application of Empathy, Clarity and Creativity could lead to these attributes becoming part of a person's make-up and contribute to overall intelligence.

In design, this creates scope to develop design processes and tools for individual and group practice, as well as interventions that could enable daily stimulation and exercising of $\mathrm{CL}$ components through ethical integration in technological and environmental solutions.

\section{Creative Leadership in innovation}

Whilst the core application of this model has been in executive education and human capital development, a review of CL project archives strongly indicates scope for applications of Creative Leadership beyond executive education. Particularly in areas of design and innovation that address human performance and wellbeing, the very same three $\mathrm{CL}$ attributes - Empathy, Clarity, and Creativity - can guide decision-making regarding the design solution, technological and economic considerations, and the individual and group experience and interaction that ensue.

$\mathrm{CL}$ was born from design and practice, and not only continues to find expression within the work of HHCD, but also proposes a framework for project delivery and innovation (Ivanova et al., 2020). A recent proposal looking at 'building competitive and resilient economies and societies through responsible $\mathrm{Al}^{\prime}$ brought together a multidisciplinary team, including designers, human-factor specialists, robot ethicists, Al developers, neuroscientists and economists to roadmap new people-centred pathways for Al. The main purpose was to explore how CL could inform a framework for development and assessment of Al technologies, as well as ensuring that CL attributes are integrated within, and consequently expressed through human-robot interactions. It was considered that guiding Al through Empathy, Clarity and Creativity, would enable the development of powerful assessment tools and platforms for people, projects, organisations and technologies, with a view to positively impacting performance and economic indicators and human wellbeing. This signified a growing opportunity area for applying $\mathrm{CL}$ as a model for innovating creatively-leading, socially-beneficial, and sustainable technologies.

\footnotetext{
${ }^{4}$ Names cannot be disclosed due to the confidentiality clause in ethics agreement
} 


\section{Future vision}

The next chapter in the evolutionary story of $\mathrm{CL}$ is a Design-Neuroscience collaboration looking to develop a blueprint for $\mathrm{CL}$. The intention for this original research is to further inform, refine and expand the theory, education, practice and applications of $\mathrm{CL}$, thereby establishing it as a responsive emerging model of leadership that empowers its practitioners with capacities and capabilities to face the unknown challenges, opportunities, and emerging reality of $21^{\text {st }}$-century markets. The combination of multi-disciplinary expertise, methods and approaches, enhanced by a shared drive to add value to others and create a positive change in the world, will ensure that the very same processes that are the foundation of $\mathrm{CL}$, are applied in practice in the evolution of $\mathrm{CL}$ theory, research and applications.

The next tranche of $\mathrm{CL}$ research and development is an acknowledgement and witnessing of the recognition that designers and neuroscientists should be working symbiotically to advance the knowledge and applications base of research evidence resulting from the intersection of both disciplines. Design based on CL theory and practice that is informed by evidence-based neuroscience has three important implications:

- Enhancing empathy, clarity, and creativity-led design typologies through learning and development strategies and methodologies informed by cognitive neuroscience knowledge and research;

- $\quad$ Re-validating older response-oriented and adaptive teaching and learning methods and environments that are wholistic and conducive to long-term memory retention and skills development. In the competitive race to digitalise training and education, these vital life-long neural implications are being largely ignored (The Royal Society, 2011).

- Increase the probability of revolutionising leadership education, skills attainment, day-to-day applications and organisational assessment criteria and algorithms, thereby positively impacting the growth and sustainability of human, social and organisational capital.

Acknowledgements: The authors would like to thank all project partners, researchers and participants to date for their generous contributions and insights, and specifically the London Doctoral Design Centre (LDoc) for funding Ivanova's post-doctoral research which brought this research team together.

\section{References}

Amabile, T., and Khaire, M. (2008). Creativity and the Role of the Leader. Harvard Business Review, 86(10), $100-109$. Begley, S. (2009). The Plastic Mind. London: Constable and Robinson.

Berlin Shcool of Creative Leadership. (2017). From creatives, to leaders. Austria: Home Town Media.

Beverland, M., Wilner, S. \& Micheli, P. (2015). Reconciling the Tension between Consistency and Relevance: Design Thinking as a Mechanism for Brand Ambidexterity. Journal of the Academy of Marketing Science, 43(5), 589-609.

Brown, T. (2008). Design Thinking. Harvard Business Review, 86(6), 84-92.

Cheron, G. (2016). How to measure psychological "flow"? A neuroscience perspective. Frontiers in Psychology, 7, 1823.

Cipresso, P. \& Immekus, J.C. (2017). Back to the future of quantitative psychology and measurement: Psychometrics in the twenty-first century. Frontiers in Psychology, 8, 2099.

Coleman, R. (1994). The Case for Inclusive Design - An Overview. Paper presented at the Proceedings of the 12th Triennial Congress, International Ergonomics Association and the Human Factors Association of Canada.

Cotton, B. (2018, November). Britain's creative industries break the $f 100 \mathrm{bn}$ barrier mark. Business Leader. Retrieved from https://www.businessleader.co.uk/britains-creative-industries-break-the-100bn-barrier-mark/56222/.

Csikszentmihalyi, M. (1975). Beyond boredom and anxiety: Experiencing flow in work and play. San Francisco, CA: Jossey-Bass. Csikszentmihalyi, M. (1996). Creativity: Flow and the psychology of discovery and invention. New York: HarperCollins.

Curedale, R. (2015). Design Thinking: Pocket Guide. Design Community College Inc, USA.

Decety, J. \& Ickes, W. (Eds.) (2009). The social neuroscience of empathy. Cambridge, MA: MIT Press.

Deloitte (2018). Insights Report: The fourth Industrial Revolution is here: are you ready? Retrieved from https://www2.deloitte.com/content/dam/Deloitte/tr/Documents/manufacturing/Industry4-0_Are-youready_Report.pdf.

Fink, A. et al. (2009). The creative brain: investigation of brain activity during creative problem solving by means of EEG and FMRI. Human Brain Mapping, 30(3), 734-748.

George, A., Marshall, M. \& Webb, J. (2018). Human origins: 7 million years and counting. John Murray Learning, Boston, MA. Gheerwo, R.. (2018, September-October). Transforming Leadership, A Creative's View. PRECIOUS, 116-125.

Gheerwo, R.. (2019). Creative Leadership: transforming individuals and organisations. dmi: review, 30(2), 4-9.

Goleman, D. \& Boyatzis, R. (2008). Social intelligence and the biology of leadership. Harvard Business Review, 86(9), 74-81. 
Gothelf, J. (2017). Lean vs. Agile vs. Design thinking: What You Really Need to Know to Build High-Performing Digital Product Teams. Gothelf Corp, USA.

Greene, J.A., Freed, R., \& Sawyer, K. (2019). Fostering creative performance in art and design education via self-regulated learning. Instructional Science An International Journal of the Learning Sciences, 47(2), 127-149.

Gruzelier, J. H. (2014a). EEG-neurofeedback for optimising performance. I: A review of cognitive and affective outcome in healthy participants. Neuroscience and Biobehavioural Reviews, 44, 124-141.

Gruzelier, J. H. (2014b). EEG-neurofeedback for optimising performance. II: Creativity, the performing arts and ecological validity. Neuroscience and Biobehavioural Reviews, 44, 142-158.

Gruzelier, J. H. (2014c). EEG-neurofeedback for optimising performance. III: A review of methodological and theoretical considerations. Neuroscience and Biobehavioural Reviews, 44, 159-182.

Harvard Business Review. (2018, November-December). The Best-Performing CEOs in the World. Harvard Business Review. Retrieved from https://hbr.org/2018/11/the-best-performing-ceos-in-the-world-2018.

HMSO. (2018). Britain's creative industries break the $\mathrm{f} 100$ billion barrier. Department for Digital, Culture, Media \& Sport and The Rt Hon Jeremy Wright QC MP. Retrieved from https://www.gov.uk/government/news/britains-creative-industriesbreak-the-100-billion-barrier.

Howick, J. (2019, May). Empathy in healthcare is finally making a comeback. The Conversation. Retrieved from: https://theconversation.com/empathy-in-healthcare-is-finally-making-a-comeback-113593

IBM. (2010). Capitalising on Complexity: Insights from the Global Chief Executive Officer Study. IBM Corporation 2010, USA.

Ivanova, N. (2018). Creative Leadership. Post-doctoral Research Fellowship Report. The Helen Hamlyn Centre for Design, Royal College of Art Unpublished.

Ivanova, N. (2019). What is Creative Leadership? dmi: review, 30(2), 6-8.

Ivanova, N., Gheerwo, R., Poggi, J., Gadzheva, I. \& Ramster, G. (2020). Towards a Gold-Standard Operations Control Centre (OCC): applying Creative Leadership principles in the re-design of an OCC at a leading Asian airline. Paper presented at the Proceedings of the $22^{\text {nd }} d m i$ : Academic Design Management Conference (dmi:ADMC2020), Toronto, Canada.

Liedtka, J., Salzman, R. \& Azer, D. (2017). Design Thinking for the Greater Good. Columbia University Press, USA.

Limb, C.J. \& Braun, A. (2008). Neural Substrates of Spontaneous Music Performance: An fMRI Study of Jazz Improvisation. PLoS ONE 3(2). Retrieved from: https://doi.org/10.1371/journal.pone.0001679.

Lyons, R. (2011). Paths to innovative leadership. BizEd Journal. Retrieved from: https://bized.aacsb.edu/articles/2011/01/pathsto-innovative-leadership.

Mainemelis, C., Ronit Kark, R. \& Epitropaki, O. (2015). Creative Leadership: A Multi-Context Conceptualization. The Academy of Management Annals, 9(1), 393-482.

McGinley, C. (2012). Supporting People-centered Design through Information and Empathy. Doctoral thesis, Brunel University, London.

McKinsey\&Company (2016) Cisco's John Chambers on the digital era. Retrieved from https://www.mckinsey.com/industries/high-tech/our-insights/ciscos-john-chambers-on-the-digital-era.

Mitchell, K., \& Reiter-Palmon, R. (2017). Creative leadership: How problem solving, decision making, and organizational context influence leadership creativity In J.C. Kaufman, V.P. Glăveanu \& J. Baer (Eds.) The Cambridge Handbook of Creativity across Domains (pp. 363-380). Cambridge University Press. https://doi.org/10.1017/9781316274385.020.

Molenberghs, P., Prochilo, G., Steffens, N.K., Zacher, H. \& Haslam, S.A. (2017). The Neuroscience of Inspirational Leadership: The Importance of Collective-Oriented Language and Shared Group Membership. Journal of Management, 43(7), 2168-2194.

Mumford, M.D., Scott, G.M., Gaddis, B., Strange, J.M. (2002). Leading creative people: Orchestrating expertise and relationships. The Leadership Quarterly, 13(6), 705-750.

Newton. K. \& Riggs, M.J. (2016). Evereybody's Talking but Who is Listening? Hearing the User's Voice Above the Noise, with Content Strategy and Design Thinking. Paper presented at VALA2016: Libraries, Technology and the Future, VALA, Australia.

Pobiner, B. (2016). The first butchers: Were there other toolmakers and meat eaters in our family tree? Retrieved from https://hominidpost.com/the-first-butchers-were-there-other-tool-makers-and-meat-eaters-in-our-family-tree/.

Puccio, G., Mance, M. \& Murdock, M. (2011). Creative Leadership: Skills That Drive Change (2nd edn.). Sage Publications.

Sawyer, K.R. (2011). The cognitive neuroscience of creativity: A critical review. Creativity Research Journal, 23(2), $137-154$.

Sawyer, K.R. (2012). Explaining Creativity: The science of human innovation. NY, US: Oxford University Press.

Selznick, P. (1957). Leadership in Administration. CA, US: Harper \& Row.

Senge, P., Smith, B., Kruschwitz, N., Laur, J., \& Schley, S. (2008). The necessary revolution: How individuals and organizations are working together to create the sustainable world. London: Nicholas Brealey Publishing.

Sohmen, V.S. (2015). Reflections on Creative Leadership. International Journal of Global Business, 8(1), 1-14.

Sporns, O., Tononi, G. \& Kötter, R. (2005) The Human Connectome: A Structural Description of the Human Brain. PLoS Comput Biol, 1(4). Retrieved from: https://doi.org/10.1371/journal.pcbi.0010042.

Sternberg, R.J., Kaufman, J.C. \& Pretz, J.E. (2003). A Propulsion Model of Creative Leadership. Creativity and Innovation Management, 13(3), 455-473.

Stoll, L. \& Temperley, J. (2009). Creative leadership: a challenge of our times. School Leadership and Management, 29(1), 65-78. 
The Royal Society. (2011). Brain waves module 2: Neuroscience: implications for education and lifelong learning. Policy Document 2 of 4, The Royal Society, London.

Trieu, M., Foster, A.E., Yaseen, Z.S., Beaubian, C., \& Calati, R. (2019). Neurobiology of empathy In A.E. Foster \& Z.S. Yaseen (Eds.) Teaching empathy in healthcare: Building a new core competency (pp. 17-39). Springer.

UK Department of Trade and Industry (2000) Foresight: Making the Future Work for You. Department of Trade and Industry, UK UK Government. (2018) Industrial Strategy: Creative Industry Sectors Deal. Retrieved from https://assets.publishing.service.gov.uk/government/uploads/system/uploads/attachment_data/file/695097/creative -industries-sector-deal-print.pdf.

van Velsor, E., McCauley, C.D. \& Ruderman, M.N. (Eds.) (2010). The Center for Creative Leadership: Handbook of Leadership Development. John Wiley \& Sons

Vavik, T. \& Gheerawo, R. (2009). The Challenges in Universal Design In T. Vavik (Ed.) Inclusive Buildings, Products \& Services: Challenges in Universal Design (pp. 4-24). Norway: Tapir Academic Press.

Vernooij, M. \& Wolfe, R. (2014, April). The Need for Creative Leadership. THNK School of Creative Leadership. Retrieved from https://www.thnk.org/insights/the-need-for-creative-leadership/. 